\title{
Development of a Simple Method for Determination of Anti-cancer Component of Indole-3-carbinol in Cabbage and Broccoli
}

\author{
Zhansheng Li ${ }^{1, *}$, Xiaochun Wei ${ }^{2}$, Lingyun $\mathrm{Li}^{1}$, Yumei Liu ${ }^{1}$, Zhiyuan Fang ${ }^{1}$, Limei Yang ${ }^{1}$, Mu Zhuang ${ }^{1}$, \\ Yangyong Zhang ${ }^{1}$, Honghao Lv $^{1}$ \\ Co-first authors: Zhansheng Li and Xiaochun Wei \\ ${ }^{1}$ Institute of Vegetables and Flowers, Chinese Academy of Agricultural Sciences, Beijing, China \\ ${ }^{2}$ Institute of Horticulture, Henan Academy of Agricultural Sciences, Zhengzhou, China \\ *Corresponding author: lizhansheng@caas.cn
}

\begin{abstract}
Indole-3-carbinol is a potential anti-cancer agent, and it has been found rich in Brassica vegetables. However, there was few good extraction method of indole-3-carbinol in cabbage and broccoli. In this work, the wavelength and the ration of mobile phase in determination method, as well as different temperature and $\mathrm{pH}$ values in extraction method were all investigated some cultivars of cabbage and broccoli were collected and validated the determination method. A sensitive and rapid high-performance liquid chromatography method has been established and used for the determination of indole-3-carbinol in cabbage (Brassica oleracea L. var. capitata) and broccoli (Brassica oleracea L. var. italica). The method was proved to be sensitive, selective, rapid and reproducible, with a good recovery of $99.25 \%$. There was a fast retention time $(4.88 \mathrm{~min})$ and good linearity $\left(\mathrm{R}^{2}=0.9991\right)$ in the system. Meanwhile, significant differences of indole-3-carbinol contents were detected among all the materials $(P<0.05)$. Finally a simple extracting method of indole-3-carbinol was established, at the same time, the determination method was shown accurate, reliable and stable. So the determination method could be proposed application in medical and industrial area.
\end{abstract}

Keywords: indole-3-carbinol, cabbage, broccoli, HPLC, anti-cancer

Cite This Article: Zhansheng Li, Xiaochun Wei, Lingyun Li, Yumei Liu, Zhiyuan Fang, Limei Yang, Mu Zhuang, Yangyong Zhang, and Honghao Lv, "Development of a Simple Method for Determination of Anti-cancer Component of Indole-3-carbinol in Cabbage and Broccoli." Journal of Food and Nutrition Research, vol. 5, no. 9 (2017): 642-648. doi: 10.12691/jfnr-5-9-3.

\section{Introduction}

Indole-3-carbinol (I3C) is the second product of hydrolysis glucobrassicin (3-indolylmethl glucosinolate), which is found in cruciferous vegetables such as broccoli, cabbages, brussels sprouts, collard greens, kale, cauliflower, kohlrabi, mustard greens, radishes, rutabaga and turnips $[1,2]$. Epidemiological and clinical studies suggest that indole-3-carbinol is a potential agent in blocking tumour initiation, oestrogen metabolism, inhibition of cell proliferation and induction of apoptosis $[3,4,5,6,7]$. So far, many studies have shown indole-3-carbinol is a bioactive component that plays an important anti-cancer role against breast [8], liver [9], prostate [10], lung and colon cancers $[11,12]$. Thus, indole-3-carbinol has been widely studied and has proved to be a potentially useful agent in cancer prevention.

Some researchers have reported that indole-3-carbinol is abundant in cruciferous vegetables because it is derived from indole-3-glusosinolate (I3G), which is found in cabbage, broccoli, kale, cauliflower, and turnip. It has been proved that consumption of cabbage juice is beneficial as an antioxidant [13] and as an anti-cancer agent $[14,15]$.

Recently, the determination methods of indole-3-carbinol have been reported by GC-MS [16] and HPLC $[17,18,19]$, which have been found in mouse plasma, mustard and Chinese cabbage $[19,20]$. Indole-3-carbinol is unstable in cell culture medium and physiological fluids since much of it is converted in the intestine to its metabolites diindolymethane (DIM) and indole carbazole (ICZ) [21]. Thus, the method of detection of indole-3-carbinol requires serious consideration. GC/MS methods require high temperatures, usually resulting in degradation of this component and, consequently, a decrease in sensitivity. HPLC methods are typically used to determine glucosinolate and their secondary products with an appropriate extraction procedure. Thus HPLC is a suitable technique for qualitative and quantitative study of indole3 -carbinol and similar compounds [17,22].

Few reports have described a simple method for the extraction and fast detection of indole-3-carbinol in Brassica vegetables. Thus, it is necessary to establish a process for the fast determination of indole-3-carbinol in vegetables. This could be useful for the selection of germplasm and biochemistry. 


\section{Materials and Methods}

\subsection{Materials and Reagents}

Fifteen cabbage cultivars and ten broccoli cultivars were bred and harvested in autumn 2015. All cultivars, including 15 cabbage varieties and 10 broccoli varieties, were obtained from the Chinese Academy of Agricultural Science (CAAS), Institute of Vegetables and Flowers (IVF). Materials were planted in a field at IVF during August 2015. At maturity, all cabbage and broccoli plants were harvested as soon as possible, and the harvest samples were quickly frozen by liquid nitrogen. All the fresh samples were dried by a freeze drying machine. Finally the dry samples were ground into powder and stored in sealed bags at $-20^{\circ} \mathrm{C}$.

Indole-3-carbinol was purchased from Sigma-Aldrich (St. Louis, MO, USA) and had a purity greater than $98 \%$. HPLC grade acetonitrile and methanol, as well as a double-distilled water Milli-Q quality water system (Millipore, Bedford, USA), were obtained from Supervision and Testing Center for Vegetable Quality, Ministry of Agriculture (Beijing, China). Sodium dihydrogen phosphates, citric acid, and ethyl acetate were purchased from Beijing chemical works (Beijing, China).

\subsection{Extraction of Indole-3-carbinol}

Powder samples $(0.5 \mathrm{~g})$ were weighed and homogenized with $15.0 \mathrm{~mL}$ of sodium dihydrogen phosphate and citric acid buffer solution and shaken for 1.5 hours in a flask, and the solvent ethyl acetate was added to the extraction by shaking for half an hour. The extracted solvent was centrifuged for $10 \mathrm{~min}$ at $5500 \times g$ in 50 -mL tubes. This procedure was repeated twice. The resulting solvent (EtOAc soluble layer) was evaporated under reduced pressure using a rotavapor (RII, BÜCHI, Switzerland) at $30^{\circ} \mathrm{C}$. The residue was then re-dissolved in $10 \mathrm{~mL}$ of methanol. The extract was filtered through Agela (China) No. $0.22-\mu \mathrm{m}$ (D $13 \mathrm{~mm}$ ) nylon filter paper and stored at $-20^{\circ} \mathrm{C}$ for HPLC determination.

We prepared a series of sodium dihydrogen phosphate and citric acid buffers with varying $\mathrm{pH}$ values of $5,5.5$, 6.0, 6.5, 7.0 and 8.0. These were used to determine an ideal condition for the indole-3-carbinol generation catalysed by myrosinase. Varying concentrations of indole-3-carbinol solution were also designed for investigation of indole-3-carbinol stabilization at $\mathrm{pH}$ values of 1.0, 2.0, 3.0, 4.0, 5.0, 6.0, 7.0 and 8.0. Samples collected at $0 \mathrm{~h}, 1 \mathrm{~h}, 2 \mathrm{~h}, 4 \mathrm{~h}, 6 \mathrm{~h}, 8 \mathrm{~h}, 12 \mathrm{~h}$ and $24 \mathrm{~h}$ from the indole-3-carbinol solutions were analysed.

Temperatures of $25^{\circ} \mathrm{C}$ (room temperature), $30^{\circ} \mathrm{C}, 50^{\circ} \mathrm{C}$ and $70^{\circ} \mathrm{C}$ were used in the experiments, and samples collected at $0 \mathrm{~h}, 1 \mathrm{~h}, 2 \mathrm{~h}, 4 \mathrm{~h}, 6 \mathrm{~h}, 8 \mathrm{~h}$ and $12 \mathrm{~h}$ were analysed. We also used this protocol to determine a condition good for the indole-3-carbinol hydrolysis reaction.

\subsection{Method Validation}

HPLC was run on an SHIMADZU LC-20A series high-performance liquid chromatography system, equipped with a CTO-20A column oven, SPD-20A UV/VIS detector,
SIL-20A HT auto-sampler, LC-20AD pump, and DGU20A3 degasser. The separation was carried out on a Waters PAH $\mathrm{C}_{18}$ column $(250 \times 4.6 \mathrm{~mm}, 5.0 \mu \mathrm{m})$. The mobile phase was optimized using water and acetonitrile, and varying ratios of water to acetonitrile were used: 70 to 30,60 to 40, 50 to 50, 30 to 70 and 40 to 60 . The peak of indole-3-carbinol was investigated and analysed.

The precision was calculated the peak areas of an indole-3-carbinol standard solution at a concentration of $50 \mathrm{mg} / \mathrm{L}$ with eight times determination of indole-3carbinol $(n=8)$, the RSD was calculated for showing the precision.

The accuracy of the determination of indole-3-carbinol was also carried out by analysing the peak areas of an indole-3-carbinol standard solution at a concentration of $49.5(n=8)$, the RSD was calculated for showing the accuracy.

Stability was calculated using the peak area of an indole-3-carbinol standard solution at a concentration of $49.5 \mathrm{mg} / \mathrm{L}$ every two hours $(\mathrm{n}=8)$, which also shown by the RSD.

Recovery was carried out by known cabbage samples spiked with indole-3-carbinol at concentrations of 10.0 $\mathrm{mg} \cdot \mathrm{L}^{-1}, 12.24 \mathrm{mg} \cdot \mathrm{L}^{-1}, 14.52 \mathrm{mg} \cdot \mathrm{L}^{-1}, 15.23 \mathrm{mg} \cdot \mathrm{L}^{-1}, 15.82$ $\mathrm{mg} \cdot \mathrm{L}^{-1}, 20.43 \mathrm{mg} \cdot \mathrm{L}^{-1}$, each treatment was extracted and analysed in triplicate $(n=3)$, and the results are shown as RSD (\%) in Table 1.

Table 1. Recovery of indole-3-carbinol results

\begin{tabular}{|c|c|c|c|c|}
\hline \multirow{2}{*}{$\begin{array}{c}\text { Cabbage } \\
\text { sample mg } \mathrm{L}-1\end{array}$} & \multirow{2}{*}{$\begin{array}{l}\text { Spiking } \\
\mathrm{mg} \cdot \mathrm{L}-1\end{array}$} & \multicolumn{3}{|c|}{ I3C } \\
\hline & & $\begin{array}{l}\text { Detection } \\
\mathrm{mg} / \mathrm{L}\end{array}$ & $\begin{array}{c}\text { Recovery } \\
\text { (\%) }\end{array}$ & RSD (\%) \\
\hline 12.53 & 10.00 & 22.01 & 97.69 & \multirow{6}{*}{1.00} \\
\hline 12.52 & 12.24 & 24.6 & 99.31 & \\
\hline 12.53 & 14.52 & 26.53 & 98.08 & \\
\hline 12.52 & 15.23 & 28.11 & 101.26 & \\
\hline 12.52 & 15.82 & 27.52 & 98.48 & \\
\hline 12.53 & 20.43 & 33.19 & 100.7 & \\
\hline
\end{tabular}

Linearity was evaluated by injecting indole-3-carbinol standard solutions with concentrations of $3.33 \mathrm{mg} \cdot \mathrm{L}^{-1}$, $10.0 \mathrm{mg} \cdot \mathrm{L}^{-1}, 20.0 \mathrm{mg} \cdot \mathrm{L}^{-1}, 50.0 \mathrm{mg} \cdot \mathrm{L}^{-1}, 100.0 \mathrm{mg} \cdot \mathrm{L}^{-1}$ and $130.0 \mathrm{mg} \cdot \mathrm{L}^{-1}$ in triplicate $(\mathrm{n}=3)$.

The determination of detection limits (LODs) and quantification limits (LOQs) was performed by analysis of the decrease in the concentration of the standard solutions. Detection limits were estimated based on a 3-to-1 signalto-noise ratio by injecting standard solutions injection in quadruplet. The quantification limits were calculated according to the formula LOQ (RSD < 5\%) = 10/3 LOD $[22,23]$.

\subsection{Application in Cabbage and Broccoli}

A total of 15 cabbage varieties and 10 broccoli varieties were collected for extract of indole-3-carbinol based on above method, and the residue was diluted in methanol.

Selectivity was determined by comparing the chromatograms of cabbage samples with those of the standard solutions. Peak identification was achieved by analysing the retention times as they appeared after the injection of indole-3-carbinol standard solutions and 
cabbage samples separately under identical conditions. In the end, the concentration of indole-3-carbinol among cabbage and broccoli varieties was recorded.

\subsection{Statistical Analysis}

Indole-3-carbinol contents, standard error (SD), and validation data were all analysed by SPSS 13.0. After one-way ANOVA, the Duncan test was performed to test the significance of the differences between mean values using a probability level of $p<0.05[16,24]$. The test data are shown as the mean values \pm SD.

\section{Results and Discussion}

\subsection{Wavelength and Eluant Selectivity of Indole-3-carbinol}

Wavelengths of 200-400 nm were scanned, and indole-3-carbinol detection was carried out at an absorption wavelength of $279 \mathrm{~nm}$ using a standard solution in methanol (Figure 1), which was consistent with previous literature $[17,19]$. The chromatogram showed a good peak with no interfering signal (Figure 2).

HPLC reverse-phase $C_{18}$ has been widely used for gluconsinolate determination $[13,25,26,27,28]$. A Waters PAH $\mathrm{C}_{18}(250 \times 4.6 \mathrm{~mm}, 5.0 \mu \mathrm{m})$ column was suitable for the separation of indole-3-carbinol. Mobile phases of methanol and water or acetonitrile and water were used at ratios 30 to 70,40 to 60,60 to 40 and 70 to 30 . The mobile phase of water and acetonitrile proved to be sensitive and able to rapidly identify and separate indole3-carbinol followed the procedure described above. Finally, the mobile phase was determined, which included water (pump A) and acetonitrile (pump B) according to the following programme: pump B was initially set at $40 \%$ acetonitrile and then linearly increased to $60 \%$ over $7 \mathrm{~min}$, after which it returned to $100 \%$. It was then allowed to equilibrate for $13 \mathrm{~min}$ at a flow rate of $0.80 \mathrm{~mL} \cdot \mathrm{min}-1$. The column temperature was $32^{\circ} \mathrm{C}$, and the injection volume was $10 \mu \mathrm{L} \cdot \min -1$.

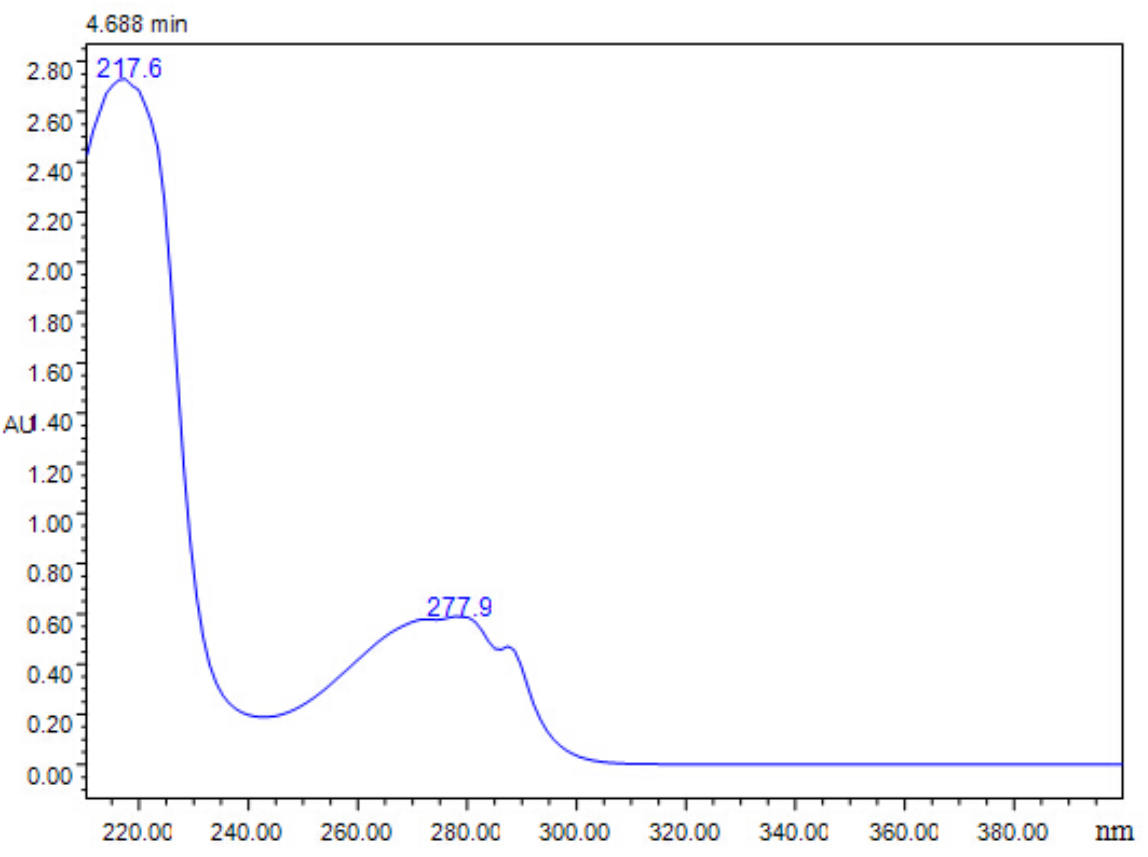

Figure 1. The UV wavelength scanning result of indole-3-carbinol from 200 to $400 \mathrm{~nm}$

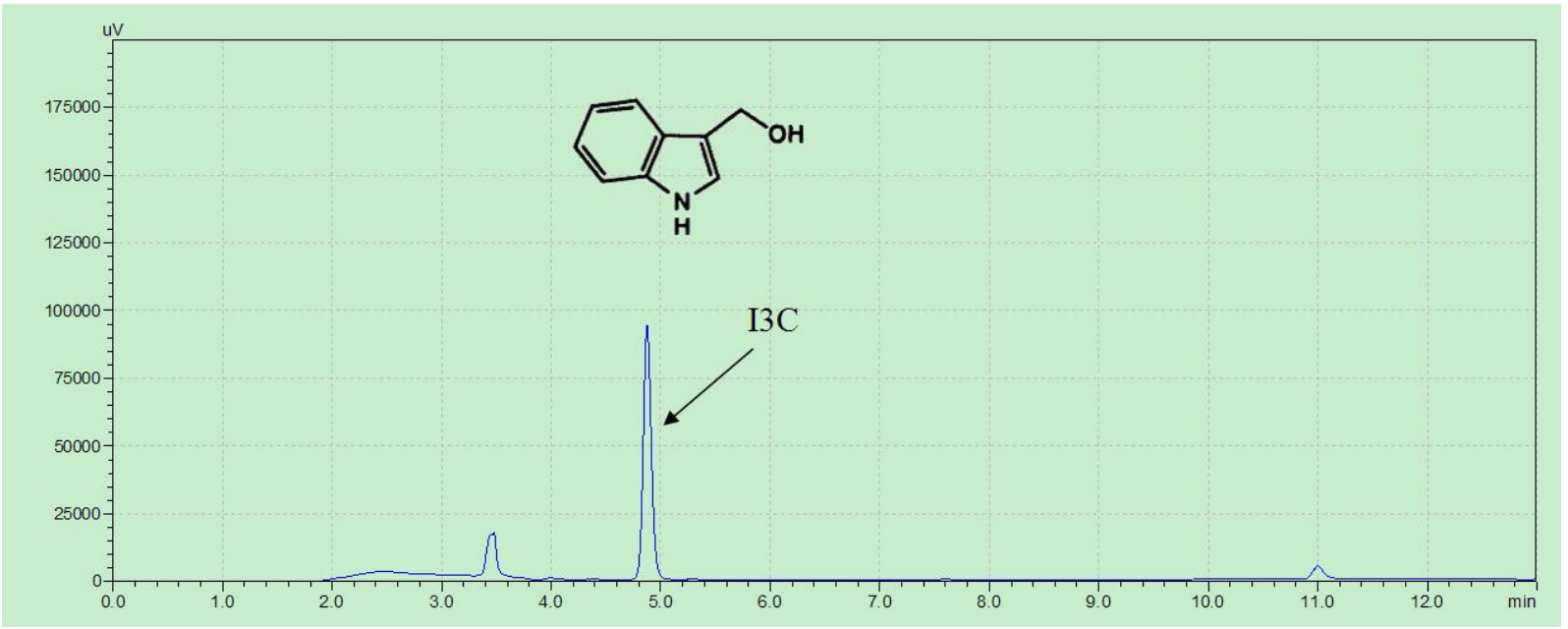

Figure 2. HPLC chromatograms of indole-3-carbinol in standard 


\section{2. pH Conditions for Hydrolysis of Indole-3-carbinol}

In this process, $\mathrm{pH}$ and temperature are the main factors that affect the generation of indole-3-carbinol catalysed by myrosinase. Thus, we examined different $\mathrm{pH}$ conditions to optimize the extraction method for indole-3-carbinol.

From the data in Figure 3, we found that there was a higher generation of indole-3-carbinol at $\mathrm{pH}$ 8.0. The results indicated that $\mathrm{pH}$ values between 5 and 6.0 were not good for indole-3-carbinol generation, and more indole-3-carbinol can be produced at a $\mathrm{pH}$ between 6.5 and 8.0. The highest amount of indole-3-carbinol was produced at $\mathrm{pH}$ 8.0. This result indicated that this alkaline environment was good for myrosinase-catalysed indole-3-carbinol generation and that this condition was good for the stabilization of indole-3-carbinol (Figure 3). Previous studies showed that $\mathrm{pH} 7.4$ was also an acceptable condition for the extraction of indole-3-carbinol; however, this condition is not the most ideal. According to this optimized study (Figure 3), we found that the alkaline condition described herein was good for the generation of indole-3-carbinol catalysed by myrosinase $[17,19]$.

\subsection{Temperature for Hydrolysis of Indole-3-carbinol}

Another factor affecting indole-3-carbinol generation is temperature; because indole-3-carbinol is not stable, fluctuations can cause aggregation into 3,3'-diindolylmethane (DIM) under strongly acidic conditions. indole-3-carbinol and its condensation product 3,3'-diindolylmethane (DIM) have both been shown to be promising anti-tumour agents from Brassica vegetables [21,29,30].

Thus, we designed a trial to test the stability of indole3-carbinol under different temperature conditions over twelve hours. According to our investigation, room temperature $\left(25^{\circ} \mathrm{C}\right)$ was an ideal condition to stabilize indole-3-carbinol, as indole-3-carbinol would degrade or convert into other components within one hour at temperatures over $50^{\circ} \mathrm{C}$ (Figure 4). As shown in Figure 4, we also found that indole-3-carbinol was relatively stable at $30^{\circ} \mathrm{C}$ in the first six hours but degraded or changed after six hours. Thus, temperatures over $25^{\circ} \mathrm{C}$ were not suitable for the storage and stability of the indole-3-carbinol solution.

In the process of indole-3-carbinol hydrolysis, myrosinase played a key role in the composition and amount of indole-3-carbinol in Brassica, similarly with sulforaphane hydrolyzed from glucoraphanin [31,32]. Myrosinase is affected by genotype, $\mathrm{pH}$, temperature, ferrous ion, zinc and magnesium concentration, which is still a complex problem in the stability of myrosinase $[19,33]$. In our study, we focused on the stability of indole-3-carbinol in the dominant factors of $\mathrm{pH}$ and temperature. There are still more works to do for investigation of myrosinase.

\subsection{HPLC System}

Compared with previous reports, the HPLC conditions described in this study allowed a sensitive and fast determination of indole-3-carbinol with a retention time of $4.8 \mathrm{~min}[11,19]$ and a reasonable run time of $13.0 \mathrm{~min}$.

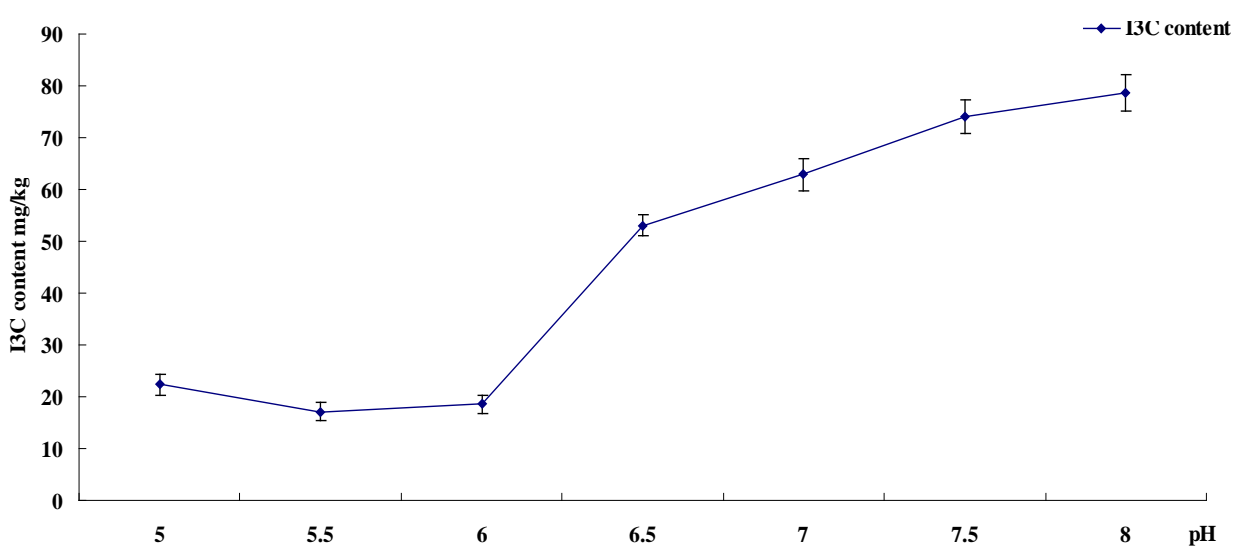

Figure 3. Hydrolysis product of indole-3-carbinol at different $\mathrm{pH}$ conditions

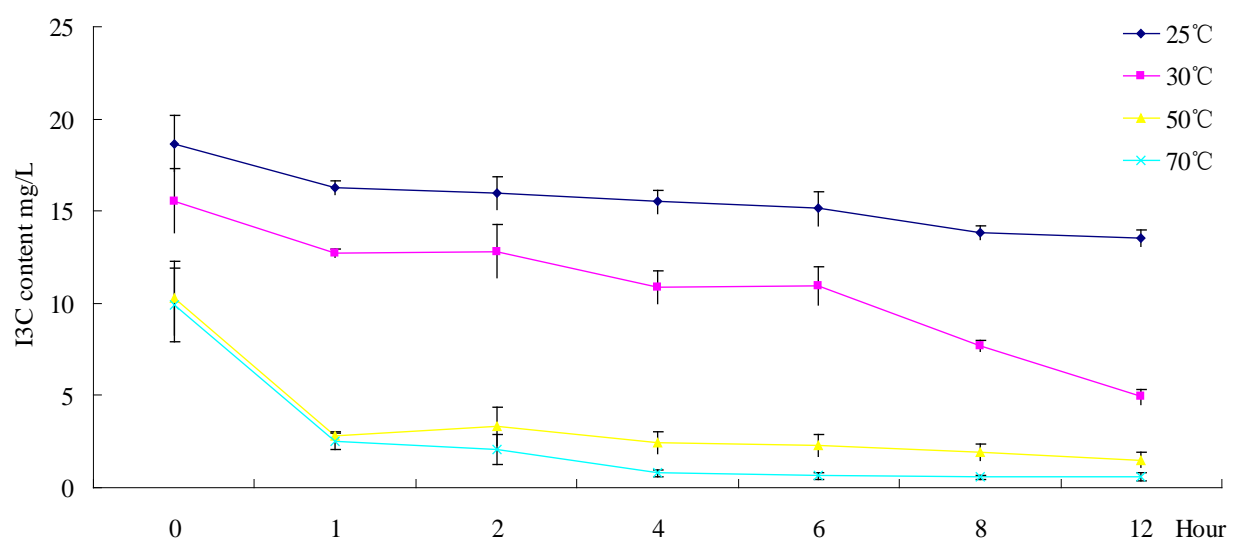

Figure 4. Stability of indole-3-carbinol in different temperature 


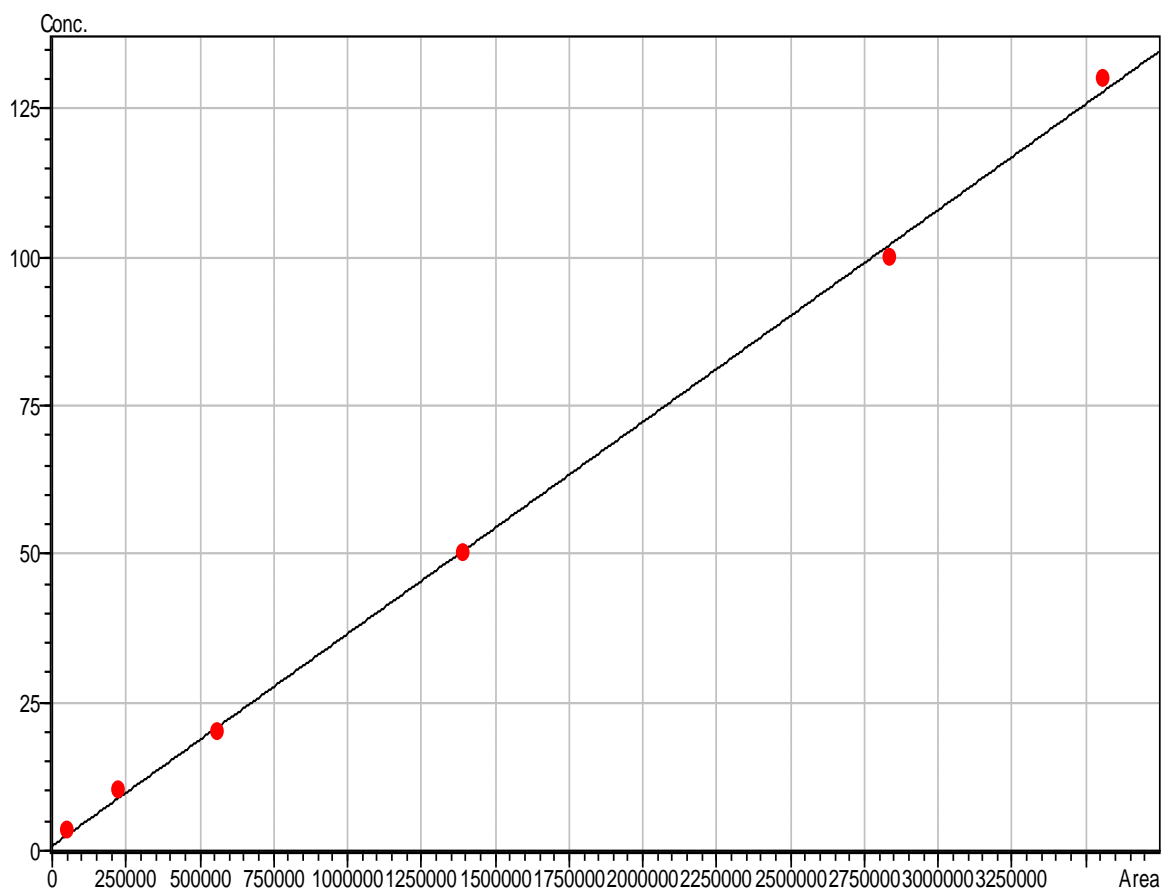

Figure 5. Calibration curve of indole-3-carbinol standard concentrations ranging from $3.33 \mathrm{mg} \cdot \mathrm{L}^{-1}$ to $130 \mathrm{mg} \cdot \mathrm{L}^{-1}$

From Figure 5, we could find there was a good linearity, the equation was $\mathrm{Y}=3.57 \times 10^{-5} \mathrm{X}+0.85, \mathrm{R}^{2}=0.9991$. According to calculation, we recorded the LOD of indole-3-carbinol was $0.02 \mu \mathrm{g} \cdot \mathrm{L}^{-1}$, meanwhile the $\mathrm{LOQ}$ was $0.07 \mu \mathrm{g} \cdot \mathrm{L}^{-1}$.

The precision of the instrument was calculated by analysing the peak areas of an indole-3-carbinol standard solution at a concentration of $50 \mathrm{mg} / \mathrm{L}$; the RSD $(n=8)$ of precision was $0.44 \%$ (Peak areas: 1410362, 1408512, 1408202, 1405097, 1402286, 1391297, 1400870 and 1400660).

The accuracy of the determination of indole-3-carbinol was also determined by analysing the peak areas of an indole-3-carbinol standard solution at a concentration of 49.5; the RSD $(n=8)$ of accuracy was $0.42 \%$ (Peak areas: 1384515, 1381645, 1377171, 1374232, 1373870, 1371607, 1369721 and 1367734).

Stability was calculated using the peak area of an indole-3-carbinol standard solution at a concentration of $49.5 \mathrm{mg} / \mathrm{L}$ every two hours $(\mathrm{n}=8)$; the average RSD (\%) was 0.32 (Peak areas: 1384515, 1381645, 1377171, 1373870, 1371607, 1373924 and 1374538).

Cabbage samples $\left(12.52 \mathrm{mg} \cdot \mathrm{L}^{-1}\right.$, I3C) were spiked with different concentrations of indole-3-carbinol following Table 1. From these results, we see that the average recovery of this method was 99.25\% (RSD=1.00\%), which suggested a good recovery based on this method.

\subsection{Application on Cabbage and Broccoli}

Fifteen cabbage cultivars and ten broccoli cultivars were extracted and validated by the HPLC method. The determined quantities of indole-3-carbinol are summarized in Table 2. All the materials were analysed and found to have a bioactive component of indole-3-carbinol, and there was a strong indole-3-carbinol peak observed (Figure 6).

In each cultivar, we detected a component of indole-3carbinol; the average indole-3-carbinol level of 15 cabbage cultivars was $28.85 \mathrm{mg} \cdot \mathrm{kg}^{-1} \mathrm{DW}$. The highest indole-3-carbinol content was in $\mathrm{C} 238\left(87.88 \mathrm{mg}^{\cdot} \mathrm{kg}^{-1}\right.$
DW), while the lowest was in C575 (6.62 $\left.\mathrm{mg} \cdot \mathrm{kg}^{-1} \mathrm{DW}\right)$. The indole-3-carbinol content in 15 cabbage cultivars ranged from 6.62 to $87.88 \mathrm{mg} \cdot \mathrm{kg}^{-1} \mathrm{DW}$. The values from every cultivar of cabbage were significantly different $(P<0.05)$. So we could infer that the genotype affect the hydrolysis product of indole-3-carbinol, which also provided indirect and more evidence for diversity of glucosinolate and hydrolysis products derived from glucosinolate, such as sulforaphane [24,34]. In this study, the cabbage C238 was demonstrated to a higher resource in indole-3-carbinol, which might provide a natural material for plant breeding, nutrition and anti-cancer research.

Table 2. The contents of indole-3-carbinol in cabbage and broccoli cultivars

\begin{tabular}{cccc}
\hline $\begin{array}{c}\text { Cabbage } \\
\text { cultivars }\end{array}$ & $\begin{array}{c}\text { Content of I3C } \\
\left(\mathrm{mg} \cdot \mathrm{kg}^{-1}\right)\end{array}$ & $\begin{array}{c}\text { Broccoli } \\
\text { cultivars }\end{array}$ & $\begin{array}{c}\text { Content of I3C } \\
\left(\mathrm{mg} \cdot \mathrm{kg}^{-1}\right)\end{array}$ \\
\hline C238 & $87.88 \pm 0.12 \mathrm{a}$ & $\mathrm{B} 2$ & $65.47 \pm 0.32 \mathrm{a}$ \\
C459 & $68.36 \pm 0.39 \mathrm{~b}$ & B33 & $64.71 \pm 0.29 \mathrm{a}$ \\
C208 & $45.51 \pm 0.44 \mathrm{c}$ & B6 & $50.38 \pm 0.36 \mathrm{~b}$ \\
C222 & $44.07 \pm 2.60 \mathrm{c}$ & $\mathrm{B} 7$ & $48.19 \pm 1.25 \mathrm{c}$ \\
C202 & $31.18 \pm 0.65 \mathrm{~d}$ & $\mathrm{~B} 1$ & $35.99 \pm 1.87 \mathrm{~d}$ \\
C543 & $30.25 \pm 1.09 \mathrm{~d}$ & $\mathrm{~B} 8$ & $22.25 \pm 2.03 \mathrm{e}$ \\
C497 & $23.43 \pm 1.37 \mathrm{e}$ & $\mathrm{B} 10$ & $20.36 \pm 0.52 \mathrm{e}$ \\
C200 & $20.14 \pm 0.57 \mathrm{f}$ & $\mathrm{B} 12$ & $15.03 \pm 0.12 \mathrm{f}$ \\
C8 & $14.94 \pm 0.56 \mathrm{~g}$ & $\mathrm{~B} 22$ & $12.17 \pm 0.45 \mathrm{~g}$ \\
C576 & $14.55 \pm 0.60 \mathrm{~g}$ & $\mathrm{~B} 28$ & $8.88 \pm 0.73 \mathrm{~h}$ \\
C475 & $13.76 \pm 0.37 \mathrm{~g}$ & & \\
C544 & $12.98 \pm 0.85 \mathrm{gh}$ & & \\
C185 & $10.92 \pm 0.55 \mathrm{~h}$ & & \\
C580 & $8.21 \pm 0.88 \mathrm{i}$ & & \\
C575 & $6.62 \pm 2.59 \mathrm{i}$ & & \\
\hline
\end{tabular}

Note: the content of indole-3-carbinol is presented as the mean \pm SD $(n=3)$; different letters indicated significant differences at the level of 5\% based on Duncan's comparison in row. 


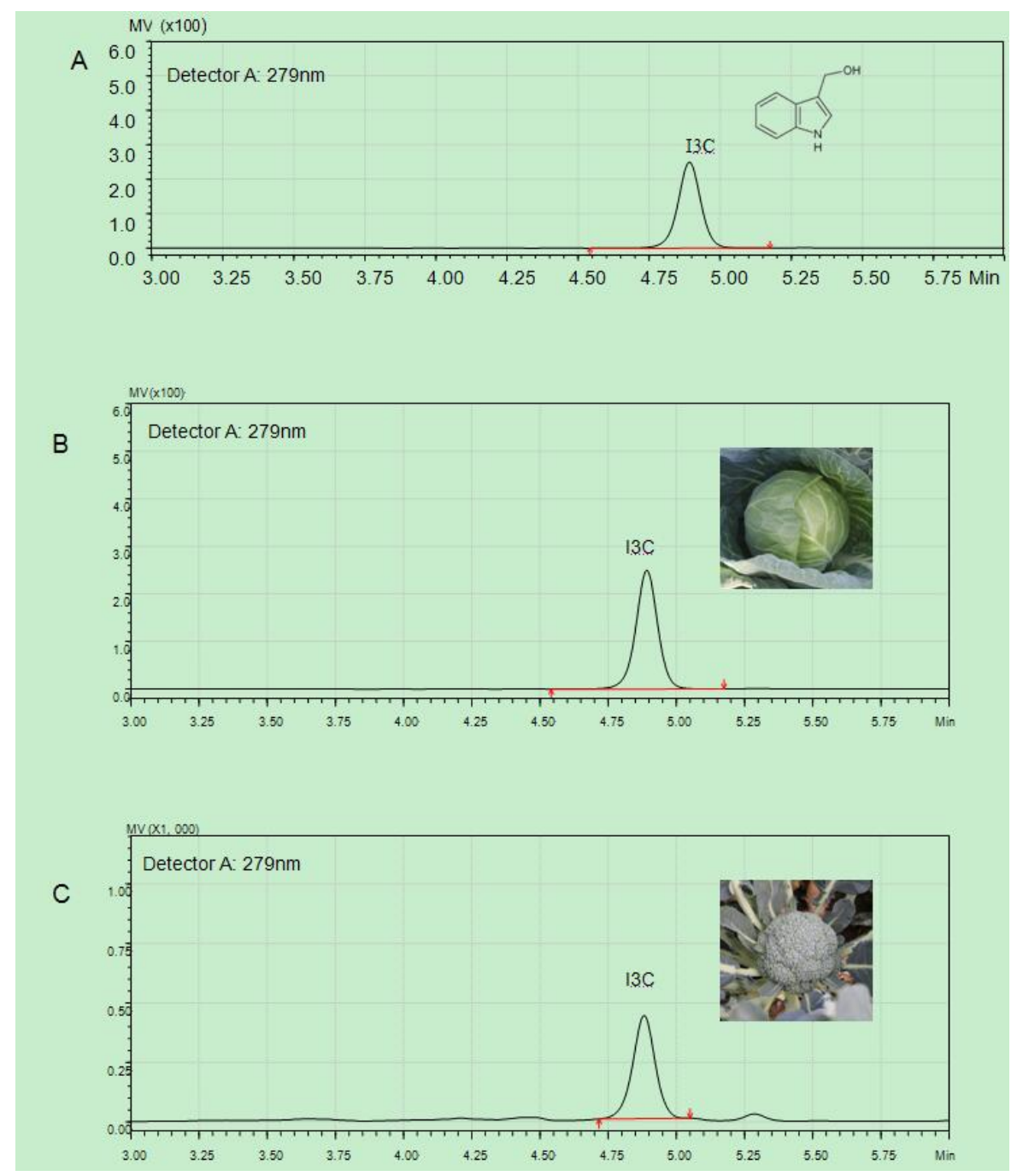

Figure 6. Chromatogram of indole-3-carbinol in standard and samples of cabbage and broccoli

Compared with the cabbage determination of indole-3carbinol, there was a smaller variation ranging from 8.88 to $65.47 \mathrm{mg} \cdot \mathrm{kg}^{-1} \mathrm{DW}$ among broccoli lines. The average indole-3-carbinol content in broccoli was $34.34 \mathrm{mg} \cdot \mathrm{kg}^{-1}$ DW, and every cultivar of broccoli was also significantly different $(P<0.05)$. The variation of indole-3-carbinol detected in broccoli was smaller than that in cabbage, which might suggest that the genetic background of indole glucosinolate in cabbage was wider than in broccoli.

The results in this study proved that the method could successfully extract indole-3-carbinol from cabbage and broccoli. The HPLC system was proved a good condition for determination of indole-3-carbinol, validating previous studies [17, 19]. All the materials including cabbage and broccoli were both detected with the anti-cancer component indole-3-carbinol. The average concentration of indole-3-carbinol in cabbage was higher than that in broccoli. However there was a smaller range of variation in broccoli, which might suggest cabbage is a good material for studying the mechanism of indole-3-carbinol in genetic analysis and metabolism. In other studies, Chinese cabbage $\left(0.63 \mathrm{mg} \cdot \mathrm{kg}^{-1} \mathrm{DW}\right)$ was determined to have a higher content of indole-3-carbinol than cabbage and broccoli, and mustard had a lower content $(0.13$ $\left.\mathrm{mg} \cdot \mathrm{kg}^{-1} \mathrm{DW}\right)[19,35]$.

In this study, we proved that cruciferous vegetables are rich in indole-3-carbinol, and genotype of Brassica affected the amount of indole-3-carbinol in hydrolysis process. And a diet rich in cruciferous vegetables, such as cabbage and broccoli, is helpful for human health and protection against cancer [36].

\section{Conclusion}

In this study, we provided a simple and rapid method for the extraction and determination of indole-3-carbinol in Brassica plants with a good recovery, such as cabbage, broccoli, Chinese kale, kohlrabi, and kale. The genotype of Brassica affected the amount of indole-3-carbinol in hydrolysis process. And $\mathrm{pH} 8.0$ was helpful for extracting of indole-3-carbinol, meanwhile the temperature should not be more than $30^{\circ} \mathrm{C}$. In fact, the method is good for the fast determination of indole-3-carbinol in medical and industry fields.

\section{Acknowledgements}

This work was supported by the National Nature Science Foundation (31501761, 31372067), the China Agriculture Research System (CARS-25-A) and the Key Laboratory of Biology and Genetic Improvement of Horticultural Crops, Ministry of Agriculture, P. R. China, 
as well as the Science and the Science and Technology Innovation Program of the Chinese Academy of Agricultural Sciences (CAAS-ASTIP-IVFCAAS).

\section{References}

[1] Kristal AR. Brassica vegetables and prostate cancer risk: A review of the epidemiologic evidence. Pharm Biol. 2002; 40: 55-8.

[2] Verhoeven DTH, Goldbohm RA, vanPoppel G, Verhagen H, vandenBrandt PA. Epidemiological studies on brassica vegetables and cancer risk. Cancer Epidem Biomar. 1996; 5: 733-48.

[3] Brandi G, Fraternale A, Lucarini S, Paiardini M, De Santi M, Cervasi B, et al. Antitumoral Activity of Indole-3-carbinol Cyclic tri- and Tetrameric Derivatives Mixture in Human Breast Cancer Cells: In Vitro and In Vivo Studies. Anti-cancer agents in medicinal chemistry. 2013; 13: 654-62.

[4] Chinni SR, Li YW, Upadhyay S, Koppolu PK, Sarkar FH. Indole3-carbinol (I3C) induced cell growth inhibition, G1 cell cycle arrest and apoptosis in prostate cancer cells. Oncogene. 2001; 20: 2927-36.

[5] Manson MM, Holloway KA, Howells LM, Hudson EA, Plummer SM, Squires MS, et al. Modulation of signal-transduction pathways by chemopreventive agents. Biochem Soc T. 2000; 28: 7-12.

[6] Manson MM, Hudson EA, Ball HWL, Barrett MC, Clark HL, Judah DJ, et al. Chemoprevention of aflatoxin B-1-induced carcinogenesis by indole-3-carbinol in rat liver - predicting the outcome using early biomarkers. Carcinogenesis. 1998; 19: 1829-36.

[7] Wong GYC, Bradlow L, Sepkovic D, Mehl S, Mailman J, Osborne MP. Dose-ranging study of indole-3-carbinol for breast cancer prevention. Journal of cellular biochemistry. 1997: 111-6.

[8] Grubbs CJ, Steele VE, Casebolt T, Juliana MM, Eto I, Whitaker LM, et al. Chemoprevention of Chemically-Induced Mammary Carcinogenesis by Indole-3-Carbinol. Anticancer research. 1995; 15: 709-16.

[9] Oganesian A, Hendricks JD, Pereira CB, Orner GA, Bailey GS, Williams DE. Potency of dietary indole-3-carbinol as a promoter of aflatoxin B-1-initiated hepatocarcinogenesis: results from a 9000 animal tumor study. Carcinogenesis. 1999; 20: 453-8.

[10] Weng JR, Tsai CH, Kulp SK, Wang D, Lin CH, Yang HC, et al. A potent indole-3-carbinol-derived antitumor agent with pleiotropic effects on multiple signaling pathways in prostate cancer cells. Cancer research. 2007; 67: 7815-24.

[11] Choi HS, Cho MC, Lee HG, Yoon DY. Indole-3-carbinol induces apoptosis through 553 and activation of caspase-8 pathway in lung cancer A549 cells. Food and Chemical Toxicology. 2010; 48: 883-90.

[12] Plate AYA, Gallaher DD. Effects of Indole-3-Carbinol and phenethyl isothiocyanate on colon carcinogenesis induced by azoxymethane in rats. Carcinogenesis. 2006; 27: 287-92.

[13] Ciska E, Verkerk R, Honke J. Effect of Boiling on the Content of Ascorbigen, Indole-3-carbinol, Indole-3-acetonitrile, and 3,3 'Diindolylmethane in Fermented Cabbage. Journal of agricultural and food chemistry. 2009; 57: 2334-8.

[14] Licznerska BE, Szaefer H, Murias M, Bartoszek A, BaerDubowska W. Modulation of CYP19 expression by cabbage juices and their active components: indole-3-carbinol and 3,3'-diindolylmethene in human breast epithelial cell lines. European journal of nutrition. 2013; 52: 1483-92.

[15] Licznerska BE, Szaefer H, Murias M, Bartoszek A, Baer-Dubowska W. Modulation of CYP19 expression by cabbage juices and their active components: indole-3-carbinol and 3,3'-diindolylmethene in human breast epithelial cell lines (vol 52, pg 1483, 2013). European journal of nutrition. 2014; 53: 995.

[16] Tolonen A, Uusitalo J, Hohtola A, Jalonen J. Determination of naphthodianthrones and phloroglucinols from Hypericum perforatum extracts by liquid chromatography/tandem mass spectrometry. Rapid Commun Mass Sp. 2002; 16: 396-402.

[17] Anderton MJ, Jukes R, Lamb JH, Manson MM, Gescher A, Steward WP, et al. Liquid chromatographic assay for the simultaneous determination of indole-3-carbinol and its acid condensation products in plasma. J Chromatogr B. 2003; 787: 281-91.
[18] Lee CH, Jeong SJ, Yun SM, Kim JH, Lee HJ, Ahn KS, et al. Down-regulation of phosphoglucomutase 3 mediates sulforaphaneinduced cell death in LNCaP prostate cancer cells. Proteome science. 2010; 8: 67.

[19] Lee SY, Chu SM, Lee SM, Kim HJ, Cho HS, Yu CY, et al. Determination of Indole-3-carbinol and Indole-3-acetonitrile in Brassica Vegetables Using High-performance Liquid Chromatography with Fluorescence Detection. J Korean Soc Appl Bi. 2010; 53: 249-52.

[20] Moussata J, Wang ZJ, Wang J. Development and validation of an HPLC method for the simultaneous quantification of indole-3carbinol acetate, indole-3-carbinol, and 3,3 '-diindolylmethane in mouse plasma, liver, and kidney tissues. J Chromatogr B. 2014; 958: 1-9.

[21] Bradlow HL, Zeligs MA. Diindolylmethane (DIM) Spontaneously Forms from Indole-3-carbinol (I3C) During Cell Culture Experiments. In vivo. 2010; 24: 387-91.

[22] Smiechowska A, Bartoszek A, Namiesnik J. Determination of Glucosinolates and Their Decomposition ProductsIndoles and Isothiocyanates in Cruciferous Vegetables. Crit Rev Anal Chem. 2010; 40: 202-16.

[23] Li ZS, Liu YM, Fang ZY, Yang LM, Zhuang M, Zhang YY, et al. Variation of Sulforaphane Levels in Broccoli (Brassica Oleracea Var. Italica) during Flower Development and the Role of Gene Aop2. J Liq Chromatogr R T. 2014; 37: 1199-211.

[24] S LZ, M LY, Y FZ, M YL, M Z, Y ZY, et al. Development and Identification of Anti-cancer Component of Sulforaphane in Developmental Stages of Broccoli (Brassica oleracea var. italica). Journal of Food and Nutrition Research. 2016; 4: 490-7.

[25] Farnham MW, Wilson PE, Stephenson KK, Fahey JW. Genetic and environmental effects on glucosinolate content and chemoprotective potency of broccoli. Plant Breeding. 2004; 123: 60-5.

[26] Giambanelli E, Verkerk R, Fogliano V, Capuano E, D'Antuono LF Oliviero T. Broccoli glucosinolate degradation is reduced performing thermal treatment in binary systems with other food ingredients. Rsc Adv. 2015; 5: 66894-900.

[27] Hanschen FS, Klopsch R, Oliviero T, Schreiner M, Verkerk R, Dekker M. Optimizing isothiocyanate formation during enzymatic glucosinolate breakdown by adjusting $\mathrm{pH}$ value, temperature and dilution in Brassica vegetables and Arabidopsis thaliana. Sci RepUk. 2017; 7.

[28] Kim JI, Dolan WL, Anderson NA, Chapple C. Indole Glucosinolate Biosynthesis Limits Phenylpropanoid Accumulation in Arabidopsis thaliana. Plant Cell. 2015; 27: 1529-46.

[29] Chen I, Mc Dougal A, Wang F, Safe S. Aryl hydrocarbon receptor-mediated antiestrogenic and antitumorigenic activity of diindolylmethane. Carcinogenesis. 1998; 19: 1631-9.

[30] Thomson CA, Ho E, Strom MB. Chemopreventive properties of 3,3'-diindolylmethane in breast cancer: evidence from experimental and human studies. Nutrition reviews. 2016; 74: 432-43.

[31] Lambrix V, Reichelt M, Mitchell-Olds T, Kliebenstein DJ, Gershenzon J. The Arabidopsis epithiospecifier protein promotes the hydrolysis of glucosinolates to nitriles and influences Trichoplusia ni herbivory. Plant Cell. 2001; 13: 2793-807.

[32] Ku KM, Becker TM, Juvik JA. Transcriptome and Metabolome Analyses of Glucosinolates in Two Broccoli Cultivars Following Jasmonate Treatment for the Induction of Glucosinolate Defense to Trichoplusia ni (Hubner). International journal of molecular sciences. 2016; 17.

[33] Liang H, Yuan QP, Xiao Q. Effects of metal ions on myrosinase activity and the formation of sulforaphane in broccoli seed. J Mol Catal B-Enzym. 2006; 43: 19-22.

[34] Malik MS, Riley MB, Norsworthy JK, Bridges W, Jr. Glucosinolate profile variation of growth stages of wild radish (Raphanus raphanistrum). Journal of agricultural and food chemistry. 2010; 58: 3309-15.

[35] Schmandke H. Indole derivatives with anticarcinogenic action from glucosinolates (GSLs) in food. Ernahrungs-Umschau. 2005; 52: 276 .

[36] Johnson F, Huff J. Development of a multi-organ rat model for evaluating chemopreventive agents: efficacy of indole-3-carbinol Certain health supplements may cause both carcinogenic and anticarcinogenic effects. Carcinogenesis. 2002; 23: 1767-8. 